\title{
Kangaroo mother care practice and its associated factors among postnatal mothers who gave birth in public general hospitals of Eastern and Central zone, Tigray, North Ethiopia
}

Haftay Gebremedhin ( $\nabla$ gebremedhinetal@gmail.com )

Adigrat University https://orcid.org/0000-0002-3307-225X

Hagos Degefa Hidru

Adigrat University

Berihu Gidey

Adigrat University

Medhin Mehari

Adigrat University

Meresa Berwo

Adigrat University

Muzayene Tilahun

Adigrat University

Haftom Legese

Adigrat University

\section{Research}

Keywords: kangaroo mother care, low birth weight, practice, newborn baby

Posted Date: August 17th, 2020

DOI: https://doi.org/10.21203/rs.3.rs-57242/v1

License: (c) (1) This work is licensed under a Creative Commons Attribution 4.0 International License. Read Full License 


\section{Abstract}

Background:

Kangaroo mother care (KMC) practice 'is the early, prolonged and continuous skin-to skin contact between the mother and her low birth weight baby that practiced in the hospital and after early discharge until at least the 40 th weeks of postnatal period with exclusive breast feeding and proper follow-up'. Low birth weight is an underling factor in $60-80 \%$ of all neonatal deaths. Therefore, this study aimed to assess kangaroo mother care practice and its associated factors among post natal mothers who gave birth in public hospitals of Eastern and Central zone, Tigray, North Ethiopia.

Methods:

An institutional based cross-sectional study was conducted in Eastern and central zone of Tigray Region from March -August/2019. A total of 411 study participants were selected using simple random sampling technique. Binary and Multiple logistic regression analysis were used to see the association of independent variables to the outcome variable at a P<0.05 using SPSS version 20.0 software.

Results:

A total of 397 study participants were included in the study with a response rate of $96.6 \%$. Of these, the mean age of the respondents was $27.4( \pm 5.7)$. More than half $(54.4 \%)$ of mothers were practiced KMC to their low birth weight baby. Mothers age [AOR $(95 \% \mathrm{Cl}): 0.21(0.05,0.95)]$, occupational status of mothers [AOR $(95 \% \mathrm{Cl}): 0.11(0.04,0.34)$ ], occupational status of fathers [AOR $(95 \% \mathrm{Cl}): 4.1(1.54,11.07)$ ], monthly income[AOR $(95 \% \mathrm{Cl}): 0.27(0.09,0.76)]$, place of delivery $[\mathrm{AOR}(95 \% \mathrm{Cl}): 0.29(0.11,0.76)$ and complications of newborn baby at birth $[A O R(95 \%): 3.1(1.21,8.09)]$ were the factors significantly associated with kangaroo mother care practice.

Conclusion:

There was low proportion of mothers practiced kangaroo mother care to their low birth weight baby. Hence, health care providers should demonstrate for family members and mothers on how to practice kangaroo mother care immediately after delivery in health institution and to be continued at home.

\section{Introduction}

Kangaroo mother care (KMC) practice is the early, prolonged and continuous skin-to skin contact between the mother and her low birth weight infant that practiced in the hospital and after early discharge until at least the $40^{\text {th }}$ weeks of postnatal period with exclusive breast feeding and proper follow-up' [1]. Prematurity was the largest direct cause of neonatal mortality, accounting for an estimated $29 \%$ of 3.6 million neonatal deaths every year. Low birth weight was an underling factor in $60-80 \%$ of all neonatal deaths [2]. Kangaroo Mother Care [KMC] is an evidence-based approach to reducing morbidity and mortality in preterm/ low birth weight baby [3-4]. Practicing of kangaroo mother care can be considered at 
three levels; mothers, fathers and families, health-care workers and facilities. Kangaroo mother care takes place in the health facility or at home [5]. Health-care workers were critical for practicing in hospitals and their main role was to educate the parents about kangaroo mother care. Mothers, fathers and families were usually the primary caregivers of low birth weight or preterm newborns and involved in decisionmaking and practice of care [6]. Majority $82 \%$ of respondents were practicing kangaroo mother care to their child at neonatal intensive care units (NICUs) [7]. Adequately implement and effectively scale-up this intervention is critical to understand the key factors that contribute to a mother's (in) ability to practice KMC [8-9]. Majority of mothers (83.3\%) did not have prior knowledge of KMC practiced. Mothers who committed to KMC, were satisfied with the results of the weight gain of the infant and indicated that they would continue to practice KMC at home. Most of them agreed that it was beneficial to both mother and infant [10].

Research from various countries also suggests that $\mathrm{KMC}$ is a cost-effective method for treating low birth weight or preterm infants [11]. In low birth weight newborns (<2500 g) who were clinically stable, kangaroo mother care reduces mortality in preterm newborns [12]. When institutional leadership did not prioritize kangaroo mother care, health-care workers were less motivated to practice, but felt empowered to do so when management allowed for roles in decision-making or promoted kangaroo mother care practice [13]. In Ethiopia, around $41.9 \%$ of mothers were practiced kangaroo mother care. Of these, $14.4 \%$ of mothers were started KMC immediately after birth as the infant had stabilized and $65.6 \%$ of them were practiced after 24 hours. Among mothers practiced KMC, 78.9\% were continued at home, $31.1 \%$ used $\mathrm{KMC}$ continuously, $53.5 \%$ used $\mathrm{KMC}$ for $1-7$ days but $4.2 \%$ were continued $\mathrm{KMC}$ practice at home for more than 15 days [14]. Kangaroo mother care practice and its associated factors were a scanty of known in Tigray Regional state. This study will help in advocacy; guidance and program development on kangaroo mother care practice, which is very important for reducing of preterm/low birth weight babies morbidity and mortality. Therefore, this study aims to investigate kangaroo mother care practice and its associated factors among postnatal mothers who gave birth to preterm/low birth weight.

\section{Materials And Methods}

\section{Study area and period}

The study was conducted in Eastern and Central zone of Tigray Regional state, North Ethiopia. Tigray is bordered by Eritrea to the North, Sudan to the west, Afar Region to the east and Amhara Region to the south. According to the projected census of 2007, the Region had a total population of 4,806,843 of these; 2,441158 (50.8\%) were women. In Eastern Zone, there were total population of 755,343, of these, 395,705 were women. In central Zone, there were total population of $1,245,824$, of these, 632,027 were women. In the two zones, there are six general hospitals [15]. The study was conducted from March August/2019 among the selected health facilities.

\section{Study design and population}


A facility based cross sectional study was employed. The source population for this study was all mothers who gave birth in all general hospitals of eastern and central zone of Tigray Regional state. All selected mothers who gave birth in the selected hospitals were also the study population. The inclusion criteria was mothers having low birth weight (LBW) baby of less than six months of age attending post natal care (PNC) visit and those who were critically ill during the study period and babies born to mothers with medically known; diabetes, hypertension, and records of incomplete data were the exclusion criteria.

\section{Sample size calculation and Sampling technique}

Sample size was calculated using single population proportion formula, ${ }^{n=\frac{(z a /)^{2} p(1-p)}{d^{2}}}$ by considering the proportion of KMC practice, $p=41.9 \% \_42 \%[14], 95 \%$ level of confidence and $5 \%$ margin of error. By adding $10 \%$ of none response rate, the final sample size needed for the study was 411 . From a total of six hospitals providing delivery services in Eastern and central zone of Tigray regional state, four hospitals were selected using simple random sampling technique namely wukro, Adigrat, Adwa, and Abieadi. Based on the total number of newborn babies taken from the respective office of the delivery registration book records, the calculated sample size was proportionally allocated to the selected hospitals. Accordingly a total of 411 study participants were selected using simple random sampling technique.

\section{Study variables}

The outcome variable for this study was Kangaroo mother care practice (Yes/No) and Sociodemographic and economic factors like mother's age, educational status, religion, occupational status, marital status and residence and Obstetric health care related variables were the independent variables.

\section{Data collection tools and procedures}

The data were collected using interviewed administered questionnaire and document review. The administrated questionnaire had socio demographic and economic conditions, obstetric health care services and practice related variables. The questionnaire was adapted from reviewing different literatures and considering the local situation of the study subjects.

\section{Data quality control}

The principal investigator trained the data collectors and supervisors for two consecutive days on instruction for the method; how to take informed written consent, how to approach participants, ethical procedure, and general information on KMC practice and the objective of the study. Ten health care providers who took the training and two MPH students were assigned as data collectors and supervisors respectively to check for the daily activity, consistency and completeness of the questionnaire and to give 
appropriate support during the data collection process. The principal investigator was checked on daily activities of supervisors and data collectors. The questionnaire was translated in to local language Tigrigna and back translated in to English by translators who were blind to the original questionnaire. The questionnaire was pre-tested on $5 \%$ of the study population in the non-selected institution to ensure clarity, wordings, logical sequence and skip patterns of the questions. After data collection, data were stored in a secured place to maintain confidentiality and backup of the data were stored in different areas not to lose the data. Each questionnaire was coded, entered and cleaning separately before analysis.

\section{Data processing and analysis}

The collected data was coded, entered, cleaned and analyzed using SPSS version 20. Descriptive statistics was used to describe KMC practice among postnatal mothers who gave birth to low birth weight baby. Frequencies and percentages were used to present categorical data. To select the candidate variables, crude ORs and their $95 \% \mathrm{Cl}$ with the $\mathrm{P}<0.2$ were estimated in the bivariate logistic regression analysis to include in the multivariable logistic regression model. After adjusted for confounders odds ratio with $95 \%$ confidence interval and $p$-value $<0.05$ were considered to declare statistically significant. Before inclusion of predictors to the final logistic regression model, the multicollinearity was checked using variance inflation factor (VIF) $<10 /$ Tolerance tests $>0.1$. The goodness of fit of the final logistic model was tested using Hosmer and lemeshow test at a value of $>0.05$.

Operational definitions: Kangaroo mother care (KMC) - Early, continuous and prolonged skin-to-skin contact between the mother and the baby with exclusive breastfeeding and proper follow-up' and it is initiated in the hospital and can be continued at home after early discharge until at least the $40^{\text {th }}$ weeks of postnatal period [14]. Low birth weight baby: infants with birth weight lower than 2500g, regardless of gestational age. KMC practiced: those mothers who scored points above or equal to the mean of KMC practice related questions; unless we consider them they did not practiced [14].

\section{Results}

\section{Sociodemographic characteristics of respondents}

A total of 397 respondents were included in the study with a response rate of $96.6 \%$. Of these, the mean age of the respondents was $27.4( \pm 5.7)$. Two hundred twenty five $(56.7 \%)$ of respondents were rural residence. More than half $239(60.2 \%)$ of respondents had their own source of income [Table-1].

\section{Obstetric related health services}

Three hundred eighty eight (97.7\%) of mothers were attending antenatal care visit. Among the respondents attending ANC, 232(58.4\%) of respondents had a frequency of four and above ANC visits. Concerning mode of delivery, 50(12.6\%) of respondents were delivered through cesarean section. Among 
a total of newborn babies, 295(74.3\%) of them had a weight of $<2500$ gram at birth. Regardless of gestational age, $212(53.4 \%)$ of respondents were greater or equal to 37 weeks of gestation during delivery followed by $105(26.4 \%)$ from $35-36$ weeks of gestation, 61 (15.4\%) from 33-34 weeks of gestation and $19(4.8 \%)$ less than or equal to 32 weeks of gestation. More than half $233(58.7 \%)$ of newborn babies were female in sex. Two hundred eighty five $(71.8 \%)$ of respondents had a history of greater than two-birth interval of the last child. One hundred thirty seven (34.5\%) of mothers were not used any family planning method. Nineteen (4.8\%) of the mothers were not taking iron/folic acid supplementation during pregnancy. Concerning TT immunization, $52(13.1 \%)$ of the mothers were not immunized. Concerning abortion, $99(24.9 \%)$ of mothers had history of abortion. Regardless of death, $64(16.1 \%)$ of mothers had history of infant death. Sixty-six (16.6\%) of mothers had history of any medical illness. From total of study participants, 45 (11.3\%) of newborn babies had congenital malformation (Table-2).

\section{Kangaroo mother care practice}

Two hundred sixteen (54.4\%) of mothers were practiced KMC to their low birth weight baby. Of these, $207(52.1 \%)$ of mothers were started KMC to their baby immediately after birth and $9(2.3 \%)$ of them were practiced after 24 hours. Among mothers practiced KMC, 186 (46.9\%) of mothers were practiced at home. Duration of KMC, $129(32.5 \%)$ of mothers were practiced KMC at home from 8-15 days followed by $63(15.9 \%)$ from $1-7$ days and $24(6 \%)$ from $16-20$ days. Among those practiced KMC, $114(28.7 \%)$ of mothers were practiced $\mathrm{KMC}$ to their baby continuously per a day and $102(25.7 \%)$ of mothers were also practiced intermittently per a day. More than half $302(76.1 \%)$ of mothers said that, health care providers were demonstrated to us how to practice KMC in health institution.

\section{Factors significantly associated towards Kangaroo mother care practice}

The multivariable logistic regression analysis showed that, those mothers in the age group of 20-24 years [AOR $(95 \% \mathrm{Cl}): 0.21(0.05,0.95)]$ were $79 \%$ more likely practiced $\mathrm{KMC}$ than those in the age group of $15-19$ years. Regarding of occupational status, mothers being employed in private sector [AOR $(95 \% \mathrm{Cl})$ : $0.11(0.04,0.34)]$ were $99 \%$ less likely practiced $\mathrm{KMC}$ than mothers worked in government employees. Concerning occupational status of fathers, being employed in private business [AOR $(95 \% \mathrm{Cl})$ : 4.1(1.54,11.07)] were 4.1 times less likely practiced KMC than those worked in government employees. Fathers being employed in private sector [AOR $(95 \% \mathrm{Cl}): 2.8(1.02,7.42)$ ] were 2.8 times less likely practiced $\mathrm{KMC}$ than fathers employed in government. Based on household monthly income, mothers who had a monthly income of greater than 3,000 Ethiopian birr [AOR $(95 \% \mathrm{Cl}): 0.27(0.09,0.76)$ ] were $73 \%$ more likely practiced KMC than mothers having monthly income of less than 500 Ethiopian birr. Mothers who gave birth in private hospitals [AOR $(95 \% \mathrm{Cl}): 0.29(0.11,0.76)$ were $71 \%$ more likely practiced KMC than who gave birth at government hospitals. Concerning complication of newborn baby, mothers who had not 
have complicated newborn baby [AOR (95\%): 3.1(1.21,8.09)] were 3.1 times more likely practiced KMC than those who had complicated newborn baby (Table-3).

\section{Discussion}

The aim of this study was to assess kangaroo mother care practice and its associated factors among postnatal mothers who gave birth in public general hospitals. Based on this we found that, age of mothers, occupational status of mother and father, household monthly income, place of delivery and complication of newborn baby at birth were the factors significantly associated with KMC practice. Many mothers who gave birth to low birth weight babies were affected by the factors identified. Therefore, the rational for this study was to help policy makers and programmers to have a clear picture about the kangaroo mother care practice and its associated factors among postnatal mothers who gave birth in public general hospitals to make an evidence based decision and mobilize resources for the prevention of low birth weight newborn death in the region. It will also guide for the heath care providers working in delivery areas to make evidence based decisions for the prevention of low birth weight newborn death.

In this study, $54.4 \%$ of mothers were practiced KMC to their low birth weight baby. Of these, $52.1 \%$ of mothers were started KMC immediately after birth and $2.3 \%$ of mothers were practiced it after 24 hours. This finding was different with a study conducted in Southern, Ethiopia [14]. This might be due to the sample size difference, study period and living condition of the population. This study showed that, among mothers practiced $\mathrm{KMC}, 46.9 \%$ of mothers were practiced $\mathrm{KMC}$ to their baby at home and 28.7 of mothers were practiced $\mathrm{KMC}$ to their baby continuously and $25.7 \%$ were also practiced intermittently. This finding was lower than a study conducted in Eastern Ethiopia and Ghana. This might be due to lack of information, and sample size difference [16-17].

This study revealed that, those mothers in the age group of $20-24$ years [AOR $(95 \% \mathrm{Cl}): 0.21(0.05,0.95)$ ] were $79 \%$ more likely practiced KMC than those in the age group of $15-19$ years. This indicated that as the age of mothers becomes higher as compared to the lowest age group, they were more awarded to practiced kangaroo mother care to their low birth weight baby. Basically $28.2 \%$ of mothers in the age group of 20-24 years were more practiced as compared mothers in the age group of 15-19 years [22.6\%]. This finding showed that, mothers being employed in private sector [AOR $(95 \% \mathrm{Cl}): 0.11(0.04,0.34)$ ] were $99 \%$ less likely practiced KMC than mothers worked in government employees. This might be due to mothers employed in private work had not had any time freedom to practiced kangaroo mother care to their low birth weight baby as compared to mothers worked in governmental institutions. In our study, fathers being employed in private business [AOR $(95 \% \mathrm{Cl}): 4.1(1.54,11.07)$ ] were 4.1 times less likely practiced KMC than those worked in government employees. Even if the proportion showed that, fathers worked in private business were $24.5 \%$ less likely practiced kangaroo mother care to their low birth weight baby than fathers worked in government institution [48.1\%]. This might be due to lack of awareness giving more attention for the growing of economic status than practiced kangaroo mother care. Based on household monthly income, mothers who had a monthly income of greater than 3,000 Ethiopian birr [AOR $(95 \% \mathrm{Cl}): 0.27(0.09,0.76)]$ were $73 \%$ more likely practiced $\mathrm{KMC}$ than mothers having monthly income of 
less than 500 Ethiopian birr. This finding showed that, mothers in low economic status were not practiced kangaroo mother care practice to their low birth weight baby. This might be mothers were more engaged in their daily laborer to survive their life of family as well as the newborn baby.

In this study, mothers who gave birth in private hospitals [AOR $(95 \% \mathrm{Cl}): 0.29(0.11,0.76)$ were $71 \%$ more likely practiced KMC than who gave birth at government hospitals. This finding was similar in a study conducted in Ethiopia. This might be due to lack of health care providers awareness on demonstrated practiced of kangaroo mother care in government hospitals [18]. In this study, mothers who had not have complicated newborn baby at birth [AOR (95\%): 3.1(1.21,8.09)] were 3.1 times more likely practiced KMC than those who had complicated newborn baby at birth. This finding was similar with a study conducted in Tikur Anbessa Hospital, Ethiopia. This might be due to mothers gave an attention to the complicated problems than practiced [19].

\section{Conclusion}

There was low proportion of mothers practiced kangaroo mother care to their low birth weight baby which was low proportion of kangaroo mother care practice immediately after birth and continuously at home. Mothers age, occupational status of mothers, occupational status of fathers, monthly income, place of delivery and newborn complications at birth were the factors significantly associated with kangaroo mother care practice. Tigray Regional Health Bureau and district health offices should use this evidence to prevent newborn death due to low birth weight in collaboration with other stakeholders. In addition, health care providers should demonstrate for family member and mothers on how to practice kangaroo mother care immediately after delivery in health institution and to be continued at home. This study addresses the kangaroo mother care practice and its associated factors among postnatal mothers who gave birth. Therefore, we recommend researchers to conduct further study on the effectiveness of kangaroo mother care practices and follow up of home based practiced of KMC to prevent newborn death due to low birth weight.

\section{List Of Abbreviations}

ANC- Ante natal care, Cl-confidence interval, HIV-human immune deficiency syndrome, KMC-Kangaroo mother care, LBW-Low birth weight, ORS-odds ratios, PNC-post natal care, SPSS-statistical package for social sciences

\section{Declarations}

\section{Ethics approval and consent to participate}

Adigrat university institutional review board approved the study and formal letter of permission was obtained from Adigrat University and Tigray Regional Health Bureau. Official letter of co-operation from the above organization was written to the respective health facilities. There was no potential risk that 
might cause any harm to respondents. The importance of the study was explained to the participation of the study and informed written consent was requested from the study subjects immediately before the data collection and written informed consent was also obtained from a parents/guardians for participants under 16 years old.

\section{Consent for publication}

Not applicable

\section{Availability of data and material}

The datasets used and/or analyzed during this study are available from the corresponding author on reasonable request.

\section{Competing interests}

The authors declare that they have no competing interests

\section{Funding}

There is no funding organization

\section{Authors' contributions}

HG was the principal investigator who contributed to the conception and design of the study, collected, entered, analyzed, interpreted the data, prepared the manuscript and acted as corresponding author. $\mathrm{HDH}$, BG, MM, MB, MT and HL were contributed to interpretation and drafted the manuscript. All authors read and approved the final manuscript.

\section{Acknowledgment}

We would like to thank to Adigrat University, Tigray regional health bureau and hospital staffs for their genuine cooperation. Our gratitude also goes to data collectors and supervisors for their hard work patience in obtaining necessary information. Our special thanks also go to participants who generously shared their thoughts and feelings despite other commitments.

\section{References}

1. Arohi Dalal, DV Bala, Sandeep kumar Chauhan $\rrbracket$. A cross-sectional study on knowledge and attitude regarding kangaroo mother care practice among health care providers. International Journal of Medical Science and Public Health. 2014, 3(3); 253-256

2. Lawn JE, Mwansa-Kambafwile J, Horta BL, Barros FC, Cousens S. 'Kangaroo mother care'to prevent neonatal deaths due to preterm birth complications. International journal of epidemiology. 2010; 39 [suppl 1]: i144-i54 
3. WHO, Kangaroo mother care a practical guide World Health Organization, 2013.

4. Ruiz Pelaez, J. G.; Charpak, N. Evidence-based clinical practice guidelines for an optimal use of the kangaroo mother method in preterm and/or low birth weight infants at birth. In Bogotá: Foundation Canguro and Department of Clinical Epidemiology and Biostatistics, School of Medicine, Pontificia Universidad Javeriana, 2007.

5. Sinha LNK, K. P., Gupta R, Dalpath S, Goyal V, Murhekar M. et al. Newborn care practices and homebased postnatal newborn care programme - Mewat, Haryana, India, 2013. West Pac Surveill Response 2014, 5(3), 22-9

6. Chisenga JZC, C. M., Ngwale M, A review of mothers' experiences at Bwaila hospital and Zomba Central hospital (Malawi). Midwifery 2015, 31(2), 305-15

7. Engler, A. J.; Ludington-Hoe, S. M.; Cusson, R. M.; Adams, R.; Bahnsen, M.; Brumbaugh, E et.al, Kangaroo care: national survey of practice, knowledge, barriers, and perceptions. $\mathrm{MCN}$ : The American Journal of Maternal/Child Nursing 2012, 27 (3), 146-153

8. Pervin, J.; Gustafsson, F. E.; Moran, A. C.; Roy, S.; Persson, L. Å.; Rahman, A., Implementing Kangaroo mother care in a resource-limited setting in rural Bangladesh. ActaPaediatrica2015, 104 (5), 458-465

9. Vesel, L.; Bergh, A.-M.; Kerber, K. J.; Valsangkar, B.; Mazia, G.; Moxon, S. G.; Blencowe, H.; et.al, Kangaroo mother care: a multi-country analysis of health system bottlenecks and potential solutions. BMC Pregnancy and Childbirth 2015, 15 (2), S5

10. Solomons N, R. C., Knowledge and attitudes of nursing staff and mothers towards kangaroo mother care in the eastern sub-district of Cape Town. S Afr J ClinNutr2012, 25 (1), 33-39

11. Nguah SB, W. P., Obeng R, Yakubu A, Kerber KJ, Lawn JE, et al., Perception and practice of Kangaroo Mother Care after discharge from hospital in Kumasi, Ghana: A longitudinal study. BMC pregnancy and childbirth 2011, 11 (1), 1

12. Conde-Agudelo A, D. -R. J. Kangaroo mother care to reduce morbidity and mortality in low birth weight infants. Cochrane Database Syst Rev 2014, 4

13. Blencowe, H.; Kerac, M.; Molyneux, E., Safety, effectiveness and barriers to follow-up using an early discharge, Kangaroo Care policy in a resource poor setting. Journal of tropical pediatrics 2009, 55 (4), 244-248

14. Ebrahim Yusuf, Firehiwot Fiseha, Dubale Dulla and Getinet kassahun. Utilization of Kangaroo Mother Care (KMC) and Influencing Factors Among Mothers and Care Takers of Preterm/Low Birth Weight Babies in Yirgalem Town, Southern, Ethiopia. Diversity and Equality in Health and Care (2018) 15(2): 87-92

15. Tigray regional health bureau profile for the 20011/12 EFY. Tigray, Mekelle, 2013

16. Roba A., Binoy S. and Naganuri M. Knowledge, Attitude and Practice of Kangaroo Mother Care by Postnatal Mothers who Gave Birth to Preterm and Low Birth Weight Babies in Public Hospitals, Eastern Ethiopia. Journal of Neonatal Biol. 2017; 6:3

17. Nguah S., Wobil P., Obeng R., Yakubu A., Kerber K., Lawn J. and Plange-Rhule G. Perception and practice of Kangaroo Mother Care after discharge from hospital in Kumasi, Ghana: A longitudinal 
study. BMC Pregnancy and Childbirth. 2011;11:99. http://www.biomedcentral.com/1471-2393/11/99

18. Weldearegay HG, Medhanyie AA, Abrha MW, Tadesse L, Tekle E, Yakob B, Girma T, Arsenault C. Quality of Kangaroo Mother Care services in Ethiopia: Implications for policy and practice. Plose one. 2019

19. Worku B., Kassie A., Mekasha A.,Tilahun B.,Worku A. Predictors of early neonatal mortality at a neonatal intensive care unit of a specialized referral teaching hospital in Ethiopia. Ethiop. J. Health Dev. 2012;26 (3):200-207

\section{Tables}

Table 1: Sociodemographic and economic characteristics of respondents, Eastern and central zone, Tigray Region, North Ethiopia, 2019

\begin{tabular}{|c|c|c|c|}
\hline \multicolumn{2}{|l|}{ Variables } & $\begin{array}{c}\text { Frequency } \\
\text { (n) }\end{array}$ & Percent \\
\hline \multirow[t]{5}{*}{ Age of mothers (Years) } & $15-19$ & 23 & $5.8 \%$ \\
\hline & $20-24$ & 102 & $25.7 \%$ \\
\hline & $25-29$ & 133 & $33.5 \%$ \\
\hline & $30-34$ & 93 & $23.4 \%$ \\
\hline & $>=35$ & 46 & $11.6 \%$ \\
\hline \multirow[t]{2}{*}{ Religion } & Orthodox & 338 & $85.1 \%$ \\
\hline & Muslim & 59 & $14.9 \%$ \\
\hline \multirow[t]{3}{*}{ Ethnicity } & Tigray & 326 & $82.1 \%$ \\
\hline & Afar & 54 & $13.6 \%$ \\
\hline & Amara & 17 & $4.3 \%$ \\
\hline \multirow[t]{3}{*}{ Marital status } & Married & 367 & $92.4 \%$ \\
\hline & Unmarried & 22 & $5.5 \%$ \\
\hline & Divorced & 8 & $2 \%$ \\
\hline \multirow[t]{3}{*}{ Educational status of mother } & Cannot read and write & 53 & $13.4 \%$ \\
\hline & $\begin{array}{l}\text { Can read and write } \\
\text { (informal) }\end{array}$ & 113 & $28.5 \%$ \\
\hline & $\begin{array}{l}\text { Read and write (Formal } \\
\text { education) }\end{array}$ & 231 & $58.2 \%$ \\
\hline \multirow[t]{3}{*}{ Educational status of father } & Cannot read and write & 13 & $30.2 \%$ \\
\hline & $\begin{array}{l}\text { Can read and write } \\
\text { (informal) }\end{array}$ & 11 & $25.6 \%$ \\
\hline & $\begin{array}{l}\text { Read and write (Formal } \\
\text { education) }\end{array}$ & 19 & $44.2 \%$ \\
\hline \multirow[t]{4}{*}{ Occupational status of mother } & Government employee & 72 & $18.1 \%$ \\
\hline & Private business & 72 & $18.1 \%$ \\
\hline & Private sector employee & 108 & $27.2 \%$ \\
\hline & House wife & 145 & $36.5 \%$ \\
\hline \multirow[t]{3}{*}{ Occupational status of father } & Government employee & 113 & $28.5 \%$ \\
\hline & Private business & 140 & $35.3 \%$ \\
\hline & Private sector employee & 144 & $36.3 \%$ \\
\hline \multirow[t]{4}{*}{ House hold monthly income: } & $<500$ Eth.birr & 29 & $12.1 \%$ \\
\hline & 500-1000 Eth.birr & 27 & $11.3 \%$ \\
\hline & 1000-3000 Eth.birr & 57 & $23.8 \%$ \\
\hline & >3000 Eth. birr & 126 & $52.7 \%$ \\
\hline
\end{tabular}


Table-2: Obstetric related health services of respondents, Eastern and central zone, Tigray Region, North Ethiopia, 2019

\begin{tabular}{|c|c|c|c|}
\hline Variables & & $\begin{array}{l}\text { Frequency } \\
\text { (n) }\end{array}$ & Percent \\
\hline \multirow[t]{4}{*}{ Number of pregnancy } & Once & 66 & $16.6 \%$ \\
\hline & Twice & 113 & $28.5 \%$ \\
\hline & Three times & 120 & $30.2 \%$ \\
\hline & More than three times & 98 & $24.7 \%$ \\
\hline \multirow[t]{2}{*}{ Frequency of ANC visit } & $<$ Four visit & 165 & $41.6 \%$ \\
\hline & $\begin{array}{l}>=\text { Four and above } \\
\text { visit }\end{array}$ & 232 & $58.4 \%$ \\
\hline \multirow[t]{2}{*}{ Meals taken per day during pregnancy } & $<3$ Meals per day & 90 & $22.7 \%$ \\
\hline & $>=$ Meals per day & 307 & $77.3 \%$ \\
\hline \multirow[t]{4}{*}{ Place of delivery } & Governmental hospital & 240 & $60.5 \%$ \\
\hline & Health center & 72 & $18.1 \%$ \\
\hline & Private hospital & 55 & $13.9 \%$ \\
\hline & Home & 30 & $7.6 \%$ \\
\hline \multirow[t]{3}{*}{ Number of delivery } & $1-2$ & 210 & $52.9 \%$ \\
\hline & $3-4$ & 153 & $38.5 \%$ \\
\hline & $>=5$ & 34 & $8.6 \%$ \\
\hline \multirow[t]{3}{*}{ Number of live births } & $1-2$ & 260 & $65.5 \%$ \\
\hline & $3-4$ & 114 & $28.7 \%$ \\
\hline & $>=5$ & 23 & $5.8 \%$ \\
\hline \multirow[t]{3}{*}{ Labor duration } & 2-6 hours & 200 & $50.4 \%$ \\
\hline & 6-12 hours & 147 & $37 \%$ \\
\hline & $>=12$ hours & 50 & $12.6 \%$ \\
\hline \multirow[t]{2}{*}{ Mode of delivery } & $\begin{array}{l}\text { Spontaneous vaginal } \\
\text { delivery }\end{array}$ & 347 & $87.4 \%$ \\
\hline & Caesarian section & 50 & $12.6 \%$ \\
\hline \multirow[t]{5}{*}{ Weight of baby at birth } & $<1000$ gram & 3 & $0.8 \%$ \\
\hline & $1000-1499$ gram & 49 & $12.3 \%$ \\
\hline & 1500-1999 gram & 103 & $25.9 \%$ \\
\hline & 2000-2499 gram & 140 & $35.3 \%$ \\
\hline & $>=2500$ gram & 102 & $25.7 \%$ \\
\hline \multirow[t]{3}{*}{ APGAR score } & Poor $<=7$ & 88 & \\
\hline & & & $22.2 \%$ \\
\hline & Good $>7$ & 309 & $77.8 \%$ \\
\hline \multirow[t]{2}{*}{ Birth interval of last child } & $<=2$ years & 112 & $28.2 \%$ \\
\hline & $>2$ years & 285 & $71.8 \%$ \\
\hline \multirow[t]{2}{*}{ Pregnancy type of last child } & Wanted and planned & 325 & $81.9 \%$ \\
\hline & $\begin{array}{l}\text { Unwanted and } \\
\text { unplanned }\end{array}$ & 72 & $18.1 \%$ \\
\hline \multirow[t]{3}{*}{ HIV status } & Reactive & 26 & $6.5 \%$ \\
\hline & Non reactive & 359 & $90.4 \%$ \\
\hline & Unknown status & 12 & $3 \%$ \\
\hline \multirow[t]{4}{*}{ Behavioral factors taken } & Cigarette smoking & 8 & $2 \%$ \\
\hline & Alcohol drinking & 58 & $14.6 \%$ \\
\hline & Chat chewing & 33 & $8.3 \%$ \\
\hline & Not taken at all & 298 & $75.1 \%$ \\
\hline
\end{tabular}


Table-3: Factors significantly associated with KMC practice among postnatal mothers who gave birth in Eastern and Central zone of Tigray, North Ethiopia, 2019

\begin{tabular}{|c|c|c|c|c|c|c|c|}
\hline \multirow[t]{2}{*}{ Variables } & & \multicolumn{2}{|c|}{ Practiced KMC } & \multirow[t]{2}{*}{ COR $(95 \% \mathrm{CI})$} & \multirow{2}{*}{$\begin{array}{l}\text { P- } \\
\text { value }\end{array}$} & \multirow[t]{2}{*}{ AOR $(95 \% \mathrm{CI})$} & \multirow{2}{*}{$\begin{array}{l}\mathrm{P} \text { - } \\
\text { value }\end{array}$} \\
\hline & & Yes & No & & & & \\
\hline \multirow[t]{5}{*}{ Age of mothers in years } & $15-19$ & $8(3.7 \%)$ & $15(8.3 \%)$ & 1 & & 1 & \\
\hline & $20-24$ & $61(28.2 \%)$ & $41(22.7 \%)$ & $0.36(0.14,0.92)$ & 0.03 & $0.21(0.05,0.95) *$ & 0.04 \\
\hline & $25-29$ & $74(34.3 \%)$ & $59(32.6 \%)$ & $0.43(0.17,1.07)$ & 0.07 & $0.30(0.07,1.37)$ & 0.12 \\
\hline & $30-34$ & $52(24.1 \%)$ & $41(22.7 \%)$ & $0.42(0.16,1.09)$ & 0.07 & $0.34(0.07,1.59)$ & 0.17 \\
\hline & $>=35$ & $21(9.7 \%)$ & $25(13.8 \%)$ & $0.64(0.23,1.79)$ & 0.39 & $0.25(0.04,1.47)$ & 0.12 \\
\hline \multirow[t]{4}{*}{ Occupational status of mother } & $\begin{array}{l}\text { Government } \\
\text { employee }\end{array}$ & $35(16.2 \%)$ & $37(20.4 \%)$ & 1 & & 1 & \\
\hline & $\begin{array}{l}\text { Private } \\
\text { business }\end{array}$ & $38(17.6 \%)$ & $34(18.8 \%)$ & $0.85(0.44,1.63)$ & 0.62 & $0.46(0.17,1.28)$ & 0.14 \\
\hline & $\begin{array}{l}\text { Private } \\
\text { sector } \\
\text { employee }\end{array}$ & $89(41.2 \%)$ & $19(10.5 \%)$ & $0.20(0.10,0.39)$ & 0.00 & $0.11(0.04,0.34)^{*}$ & 0.00 \\
\hline & House wife & $54(25 \%)$ & $91(50.3 \%)$ & $1.59(0.90,2.82)$ & 0.11 & $1.00(0.33,3.03)$ & 0.99 \\
\hline \multirow[t]{3}{*}{ Occupational status of father } & $\begin{array}{l}\text { Government } \\
\text { employee }\end{array}$ & $60(27.8 \%)$ & $53(29.3 \%)$ & 1 & & 1 & \\
\hline & $\begin{array}{c}\text { Private } \\
\text { business }\end{array}$ & $53(24.5 \%)$ & $87(48.1 \%)$ & $1.86(1.12,3.07)$ & 0.02 & $4.1(1.54,11.07) *$ & 0.00 \\
\hline & $\begin{array}{l}\text { Private sector } \\
\text { employee }\end{array}$ & $103(47.7 \%)$ & $41(22.7 \%)$ & $0.45(0.27,0.76)$ & 0.00 & $2.8(1.02,7.42)^{*}$ & 0.04 \\
\hline \multirow[t]{4}{*}{ House hold monthly income } & $<500$ Eth.birr & $12(9 \%)$ & $17(16.2 \%)$ & 1 & & 1 & \\
\hline & $\begin{array}{l}\text { 500-1000 } \\
\text { Eth.birr }\end{array}$ & $13(9.7 \%)$ & $14(13.3 \%)$ & $0.76(0.26,2.19)$ & 0.61 & $0.71(0.19,2.62)$ & 0.61 \\
\hline & $\begin{array}{l}\text { 1000-3000 } \\
\text { Eth.birr }\end{array}$ & $23(17.2 \%)$ & $34(32.4 \%)$ & $1.04(0.42,2.59)$ & 0.93 & $0.88(0.28,2.83)$ & 0.83 \\
\hline & $\begin{array}{l}>3000 \text { Eth. } \\
\text { birr }\end{array}$ & $86(64.2 \%)$ & $40(38.1 \%)$ & $0.33(0.14,0.75)$ & 0.01 & $0.27(0.09,0.76) *$ & 0.01 \\
\hline \multirow[t]{4}{*}{ Place of delivery } & $\begin{array}{l}\text { Governmental } \\
\text { hospital }\end{array}$ & $97(44.9 \%)$ & $143(79 \%)$ & 1 & & 1 & \\
\hline & Health center & $52(24.1 \%)$ & $20(11 \%)$ & $0.26(0.15,0.46)$ & 0.00 & $0.42(0.17,1.03)$ & 0.06 \\
\hline & $\begin{array}{l}\text { Private } \\
\text { hospital }\end{array}$ & $45(20.8 \%)$ & $10(5.5 \%)$ & $0.15(0.07,0.31)$ & 0.00 & $0.29(0.11,0.76) *$ & 0.01 \\
\hline & Home & $22(10.2 \%)$ & $8(4.4 \%)$ & $0.25(0.11,0.58)$ & 0.00 & $0.42(0.13,1.35)$ & 0.15 \\
\hline \multirow[t]{3}{*}{ Number of delivery } & $1-2$ & $102(47.2 \%)$ & $108(59.7 \%)$ & 1 & & 1 & \\
\hline & $3-4$ & $96(44.4 \%)$ & $57(31.5 \%)$ & $0.56(0.37,0.86)$ & 0.01 & $0.73(0.35,1.54)$ & 0.41 \\
\hline & $>=5$ & $18(8.3 \%)$ & $16(8.8 \%)$ & $0.84(0.41,1.74)$ & 0.64 & $0.80(0.24,2.65)$ & 0.72 \\
\hline \multirow[t]{2}{*}{ Complication of newborn baby } & Yes & $36(16.7 \%)$ & $38(21 \%)$ & 1 & & 1 & \\
\hline & No & $180(83.3 \%)$ & $143(79 \%)$ & $0.75(0.45,1.25)$ & 0.27 & $3.1(1.21,8.09)^{*}$ & 0.02 \\
\hline
\end{tabular}

95\% CI- 95\% Confidence interval, COR- Crud odds ratio, AOR- Adjusted odds ratio

* Statistically significant variables 